\title{
PEMBUATAN RUMAH IKAN (RUMPON) LUBUK LARANGAN DI DUSUN TEBAT KABUPATEN BUNGO PROVINSI JAMBI
}

\author{
${ }^{1 *}$ Muhammad Natsir Kholis, ${ }^{2}$ Rini Hertati, ${ }^{3}$ Mohd. Yusuf Amrullah \\ Universitas Muara Bungo, Jambi, Indonesia \\ Email : *siginjai1981@gmail.com
}

Manuskrip: Desember -2021; Ditinjau: Januari -2022; Diterima: Januari -2022; Online: Januari-2022; Diterbitkan: Januari-2022

\begin{abstract}
ABSTRAK
Salah satu pengembangan dari lubuk larangan yaitu dengan menerapkan teknologi rumah ikan (rumpon). Rumpon di lubuk larangan ini diharapkan menjadi solusi dari keberadaan lubuk larangan sebagai habitat ikan agar tetap eksis. Tujuan pengabdian masyarakat yaitu memperkenalkan dan membuat rumpon di desa tebat Kabupaten Bungo Provinsi Jambi. Hasil pengabdian masyarakat ini dapat disimpulkan bahwa masyarakat masih belum banyak mengenal rumpon, pembuatan rumpon dilakukan bersama masyarakat dan dioperasikan di lubuk larangan tebat. Konstruksi rumpon yang dibuat memliki pelampung berdiameter 80 $\mathrm{cm}$ dan tinggi $30 \mathrm{~cm}$, tali berbahan PE dengan panjang $1.5 \mathrm{~m}$ berdiameter $1 \mathrm{~cm}$, badan rumpon terbuat dari rangka bambu dan kayu berukuran panjang $80 \mathrm{~cm}$, lebar $50 \mathrm{~cm}$ dan tinggi $1.54 \mathrm{~m}$. Atraktor rumpon yaitu daun sawit panjang $1.9 \mathrm{~m}$ berjumlah 5 helai serta pemberat berbahan semen.
\end{abstract}

\section{Kata Kunci: Desa Tebat, Jambi, Lubuk Larangan, Rumpon}

\section{PENDAHULUAN}

Lubuk larangan merupakan daerah aliran sungai (DAS) Batanghari yang memiliki kedalaman dan airnya tenang, tempat ini menjadi tempat yang kondusif untuk perkembangbiakan ikan. Masyarakat dilarang keras untuk mengambil ikan di wilayah lubuk larangan ini hingga waktu yang telah disepakati bersama. Di provinsi Jambi, tradisi lubuk larangan ini sebagian masih diterapkan, utamanya di daerah pedalaman kampung seperti di Kabupaten Bungo, Merangin dan wilayah lainnya. Bagi desa yang menerapkan lubuk larangan ini, biasanya untuk menjaga kesepakatan bersama, mereka mengucapkan sumpah bersama, namun ada juga warga yang nekat melanggar sumpah, alhasil bagi pelanggar sumpah bisa berakibat sakit bahkan meninggal dunia (Handayani et al., 2018; Harizon et al., 2020)

Pada saat panen ikan tiba masyarakat menggelar upacara pencabutan sumpah yang dilakukan tuo-tuo tengganai, alim ulama setempat dan biasanya dilakukan di masjid desa. Tradisi lubuk larangan merupakan salah satu tradisi kearifan lokal yang sangat bermanfaat untuk menjaga kelestarian lingkungan. Tidak hanya di provinsi Jambi, beberapa wilayah di Sumatera juga menerapkan hal yang sama (CIFOR, 2008). Salah satu daerah yang menerapkan tradisi lubuk larangan yaitu 
desa tebat, daerah ini memiliki dua lubuk larangan yang dapat dikelola masyarakat. Hasil panen masyarakat desa tebat berkisar 50-100 kg sekali panen jangka waktu tertentu

Lubuk larangan terus berkembang dari satu dusun ke dusun lainnya. Pada akhir tahun 2018 tercatat jumlah lubuk larangan di Kabupaten Bungo berjumlah 128 lubuk (Disnakkan Kabupaten Bungo, 2018; Kholis et al., 2020).

Keberadaan lubuk larangan merupakan salah satu wujud upaya konservasi sumberdaya perikanan yang memiliki peranan penting bagi masyarakat. Tata cara pembentukan kawasan konservasi itu telah diatur dalam Peraturan Pemerintah Nomor 60 Tahun 2007 Tentang Konservasi Sumber Daya Ikan dan Peraturan Menteri Kelautan dan Perikanan RI Nomor PER.02/MEN/2009 Tentang Tata Cara Penetapan Kawasan Konservasi Perairan.

Keberadaan suaka perikanan secara hukum dijamin berdasarkan pada Undang-undang Nomor 45 Tahun 2009 tentang perikanan, Peraturan Pemerintah Nomor 60 Tahun 2007 tentang konservasi sumberdaya ikan. Sedangkan tata cara penetapan kawasan konservasi perairan diatur dengan Peraturan Menteri Kelautan dan Perikanan No: PER.02/MEN/2009. Berdasarkan tujuan pengelolaan, suaka perikanan memiliki kriteria: tempat hidup dan berkembang biak satu atau lebih jenis ikan tertentu yang perlu dilindungi dan dilestarikan; memiliki satu atau beberapa tipe ekosistem sebagai habitat jenis ikan tertentu yang relatif masih alami; dan/atau memiliki luas perairan yang mendukung keberlangsungan proses ekologis secara alami sebagai habitat ikan serta dapat dikelola secara efektif.

Salah satu pengembangan dari lubuk larangan yaitu dengan menerapkan teknologi rumah ikan (rumpon). Rumpon di lubuk larangan ini diharapkan menjadi solusi dari keberadaan lubuk larangan sebagai habitat ikan agar tetap eksis. Selain untuk menjaga perkembangbiakkan ikan, rumpon lubuk larangan ini berguna juga untuk meningkatkan hasil tangkapan saat pembukaan lubuk larangan (panen), karena ikan sudah banyak berkumpul di sekitar rumpon (Kholis et al., 2020).

\section{MASALAH}

Permasalahan yang dihadapi mitra saat ini yaitu sulitnya mencari ikan saat panen lubuk larangan. Mencari ikan saat panen menjadi masalah karena tidak semua ikan yang ada di lubuk larangan menetap di lubuk larangan, karena pergerakan ikan tidak bisa dikontrol atau diduga. Hal ini membutuhkan akses teknologi prototipe untuk membuat ikan nyaman dan betah tinggal menetap di lubuk larangan. Sehingga masyarakat bisa dengan mudah menangkap ikan karena ikan sudah berkumpul di sekitar lubuk dengan solusi membuat rumah ikan (rumpon). Adapun tujuan dari pengabdian masyarakat ini yaitu memperkenalkan dan membuat rumpon di Desa Tebat Kabupaten Bungo Provinsi Jambi

\section{METODE PELAKSANAAN KEGIATAN}

\section{Solusi Permasalahan}

Keterbatasan perkembangan IPTEK di dusun tebat membuat lubuk larangan tidak berkembang, maka solusi yang tepat yaitu dengan membuat 
rumah ikan (rumpon) sebagai bentuk pengembangan lubuk larangan kedepannya, agar membuat ikan semakin nyaman dan betah menetap di sekitar lubuk larangan. Dengan adanya rumah ikan (rumpon) maka ikan akan terkosentrasi disekitar rumah ikan (rumpon) sehingga keberadaan ikan di lubuk larangan tetap terjaga. Menurut Suardi (2017) konstruksi rumpon hidup (BioFAD) hasil rancangannya berbentuk silinder atau tabung mampu memikat ikan yang berukuran juvenil maupun ikan yang berukuran dewasa.

2. Metode Pelaksanaan

\section{Bentuk Kegiatan :}

Kegiatan pengabdian masyarakat ini dihadiri \pm 15 orang dari masyarakat desa tebat yang berprofesi sebagai nelayan sambilan. Kegiatan dilakukan dengan penyuluhan, pelatihan dan pendampingan.

a. Penyuluhan

Untuk menambah wawasan mitra dan kelompoknya maka kami melakukan penyuluhan tentang pengenalan rumpon dan teknik pembuatan rumpon.

b. Pelatihan

1. Setelah diberikan wawasan kami akan melatih mitra dengan tahapan: persiapan alat dan bahan

2. Melatih mitra membuat rumah ikan (Rumpon)

3. Melatih mitra meresparasi atau memperbaiki rumah ikan yang sudah lama di letakan pada perairan.

c. Pendampingan

Pendampingan dilakukan dengan memantau dan membantu mitra agar mampu membuat rumah ikan (rumpon) dan mengelola sumberdaya perairan yang ada di lubuk larangan. Proses pendampingan juga melihat bagaimana prospek dan hasil dari kegiatan pengabdian ini agar dapat berkelanjutan.

\section{Alat dan Bahan}

Alat yang digunakan pada pengabdian masyarakat ini yaitu: laptop, infokus, pointer, kayu, bamboo, palu, gunting, meteran. Sedangkan bahan yang digunakan yaitu: semen, paku, tali PE, pasir, daun sawit.

\section{Teknik Pengumpulan Data}

Teknik survei, partisipatif, observasi dan wawancara dipilih sebagai teknik pengumpulan data primer. Data sekunder diperoleh dari laporan dinas terkait baik yang terpublikasi maupun yang tidak terpublikasi serta li teratur terkait lainnya.

\section{Analisis Data}

Analisis data yang digunakan dalam pengabdian masyarakat ini yaitu deskriptif, dengan menggambarkan keadaan yang sebenarnya dilapangan dan hasil pengamatan selama pengabdian.

\section{Waktu dan Tempat Pelaksanaan}

Pengabdian kepada masyarakat ini di laksanakan pada Bulan Juni 2021 di desa tebat Kabupaten Bungo Provinsi Jambi (Gambar 1). 


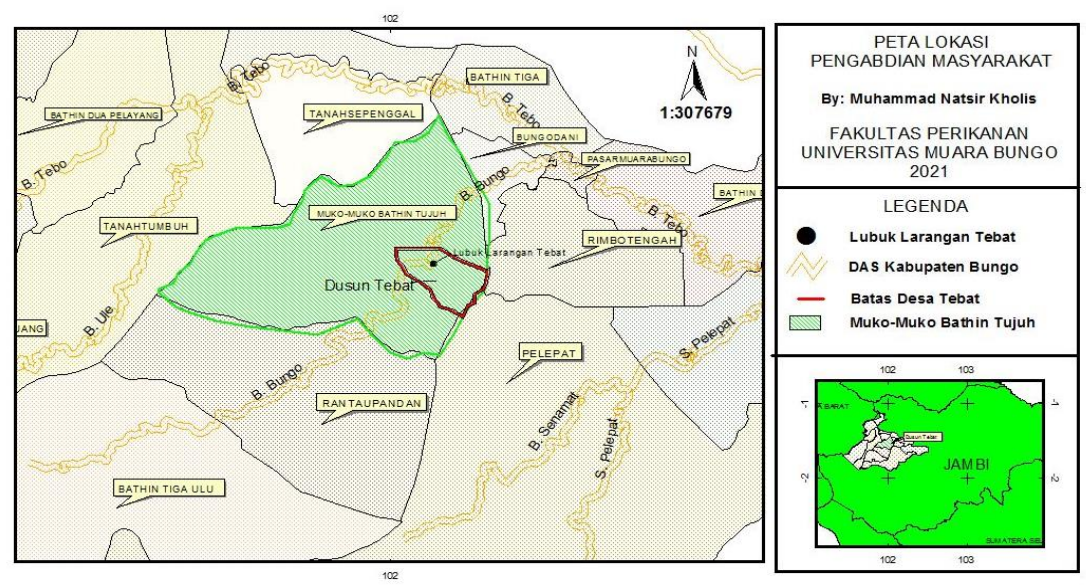

Gambar 1. Peta Lokasi Pengabdian Masyarakat

\section{HASIL DAN PEMBAHASAN}

Penyuluhan Rumpon

Kegiatan penyuluhan diawali dengan kata sambutan RIO (kepala desa), perwakilan dosen, kemudian membaca doa dan ramah tamah. Kegiatan penyuluhan rumpon dilakukan dengan cara menyampaikan materi kepada masyarakat tentang pengertian rumpon, kegunaan rumpon \& interaksinya terhadap ikan, jenis-jenis rumpon, serta cara pembuatannya. Kegiatan ini berlangsung \pm 120 menit. Masyarakat sangat antusias terhadap materi yang disampaikan sehingga diskusi berlangsung secara timbal balik. Beberapa pertanyaan masyarakat yang menjadi catatan pemateri yaitu: bantuan dana pengadaan rumpon, rumpon hilang di perairan atau hanyut terbawa arus sungai dan penempatan rumpon yang baik.

Untuk bantuan dana rumpon memang belum ada di Kabupaten Bungo, karena rumpon belum familiar di masyarakat, tetapi bisa saja dianggarkan pemerintah dengan cara masyarakat membuat proposal pengadaan rumpon secara berkelompok. Kemudian solusi agar rumpon tidak hilang yaitu dengan memperhatikan posisi penempatan rumpon dan pemberat yang digunakan harus mampu menahan beban dari rumpon yang dibuat. Terakhir untuk penempatan rumpon yang baik yaitu lokasi perairannya tenang dan aman, kualitas perairan baik, merupakan habitat/ruaya ikan, tidak menganggu aktivitas mayarakat dan mendapat izin pemerintah atau kelompok masyarakat. Dokumentasi kegiatan penyuluhan rumpon dapat dilihat pada gambar dibawah ini
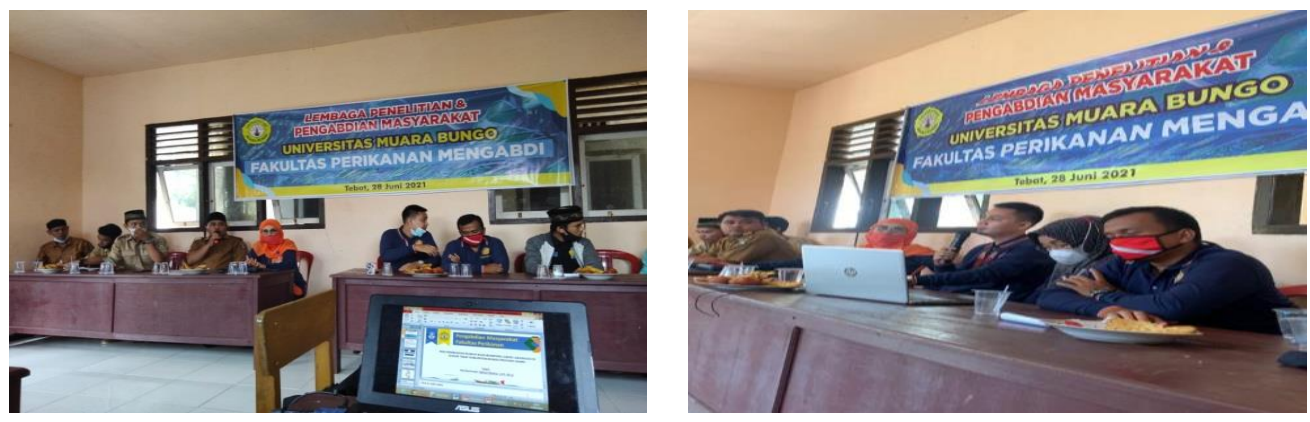

Gambar 2. Penyuluhan Rumpon 


\section{Pembuatan dan Pemasangan Rumpon}

Setelah penyuluhan dan penyampaian materi, kegiatan pengabdian masyarakat selanjutnya yaitu praktek pembuatan rumah ikan (rumpon). Pembuatan rumpon diawali dengan mempersiapkan alat dan bahan, kemudian perancangan/konstruksi bentuk rumpon (Gambar 3) dan terakhir perakitan rumpon (Gambar 4). Bentuk rumpon yang dibuat yaitu berbentuk persegi panjang dengan atraktor daun sawit. Perbedaan konstruksi dan desain rumpon disetiap wilayah adalah hal yang mutlak, mengingat letak geografis Indonesia yang merupakan negara kepulauan. Hal yang penting dalam membuat rumpon yaitu ketersediaan bahan baku, daya tahan rumpon terhadap berbagai kondisi perairan dan mudah dioperasikan (Yusfiandayani et al., 2014). Secara umum rumpon pada prinsipnya terdiri dari empat komponen utama, yaitu: 1) pelampung (float); 2) tali-temali; 3) atraktor atau pemikat dan 4) pemberat atau sinker.

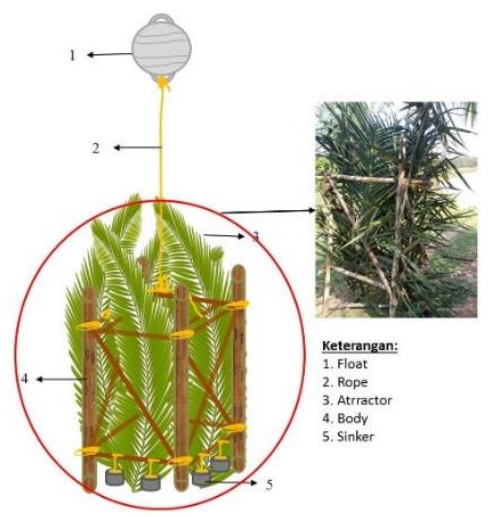

Gambar 3. Konstruksi Rumah Ikan (Rumpon)

Konstruksi rumpon yang dibuat memliki pelampung berdiameter $80 \mathrm{~cm}$ dan tinggi $30 \mathrm{~cm}$, tali berbahan PE dengan panjang $1.5 \mathrm{~m}$ berdiameter $1 \mathrm{~cm}$, badan rumpon terbuat dari rangka bamboo dan kayu berukuran panjang $80 \mathrm{~cm}$, lebar 50 $\mathrm{cm}$ dan tinggi $1.54 \mathrm{~m}$. Atraktor rumpon yaitu daun sawit panjang $1.9 \mathrm{~m}$ berjumlah 5 helai serta pemberat berbahan semen cor. Menurut Kholis et al., (2020) atraktor yang digunakan rumpon lubuk larangan hasil perancangannya menggunakan atraktor tali rapia dan paralon, tetapi atraktor tersebut kurang efektif dalam memikat ikan yang ada di lubuk larangan desa tebat, dan sebagian masyarakat kurang setuju dengan penggunaan tali rapia karena terbuat dari bahan sintetis. Atraktor daun sawit (serat alami) yang digunakan sama dengan hasil penelitian Hikmah et al., (2017) yang menggunakan atraktor berbahan daun kelapa dengan panjang $3.7 \mathrm{~m}$ berjumlah 8 sampai 25 helai. Menurutnya pemilihan jenis aktraktor daun kelapa memberi peluang tumbuhnya mikroorganisme penempel pada permukaan daun kelapa sebagai sumber nutrien bagi ikan pelagis kecil

Secara umum konstruksi rumpon yang dibuat merupakan hasil pengamatan di lapangan, dengan memperhatikan kondisi perairan dan jenis spesies yang ada di lubuk larangan. Jenis ikan yang banyak terdapat di lubuk larangan merupakan ikan yan memiliki tingkah laku (behaviour) bersembunyi dan berteduh. 

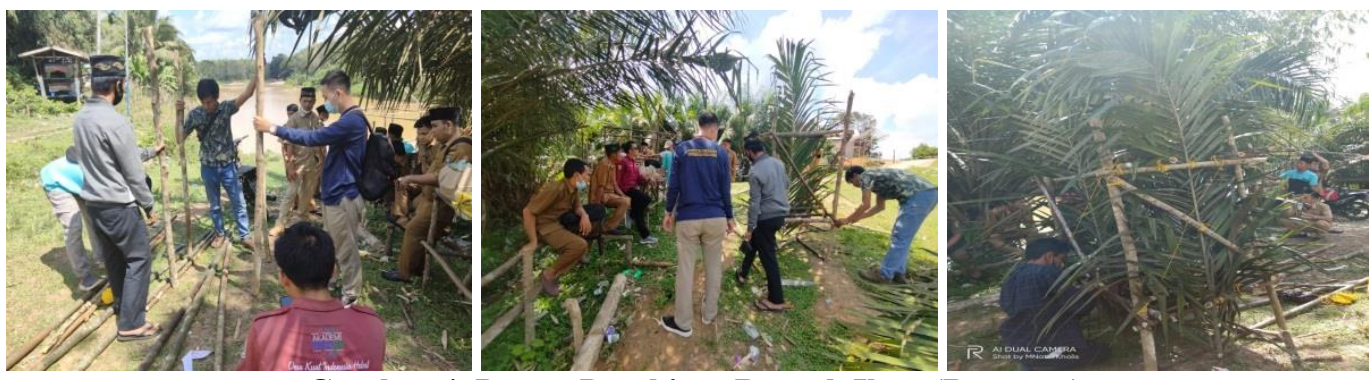

Gambar 4. Proses Perakitan Rumah Ikan (Rumpon)

Pemasangan atau pengoperasian rumpon menurut Kholis et al., (2020) yaitu dengan membawa rumpon yang telah dibuat menuju lokasi pemasangan/penempatan rumpon, yaitu lubuk larangan desa tebat. Lubuk larangan desa tebat ini merupakan aliran sungai batang bungo. Jumlah nelayan/orang yang dibutuhkan dalam pengoperasinnya berkisar 5 sampai 10 orang. Penurunan rumpon dilakukan dengan menjatuhkan bagian bawah rumpon (pemberat), dengan dua orang menahan badan rumpon, satu orang menahan tali pelampung secara perlahan dari atas permukaan perairan, dan dua orang menyelam untuk memastikan rumpon jatuh pada posisi yang benar di dasar perairan. Setelah rumpon sampai di dasar perairan, maka pelampung akan mengapung diatas perairan. Kedalaman lubuk larangan berkisar 2 sampai 4 meter dengan lebar \pm 25 meter dan panjang bisa mencapai $1 \mathrm{~km}$ tergantung lokasi lubuk larangannya. Rumpon lubuk larangan ini bersifat menetap, sehingga ikan yang berada dirumpon lubuk larangan dapat berkembang biak secara alamiah. Waktu yang diperlukan untuk menurunkan/memasang rumpon ini berkisar antara 30 sampai 60 menit.

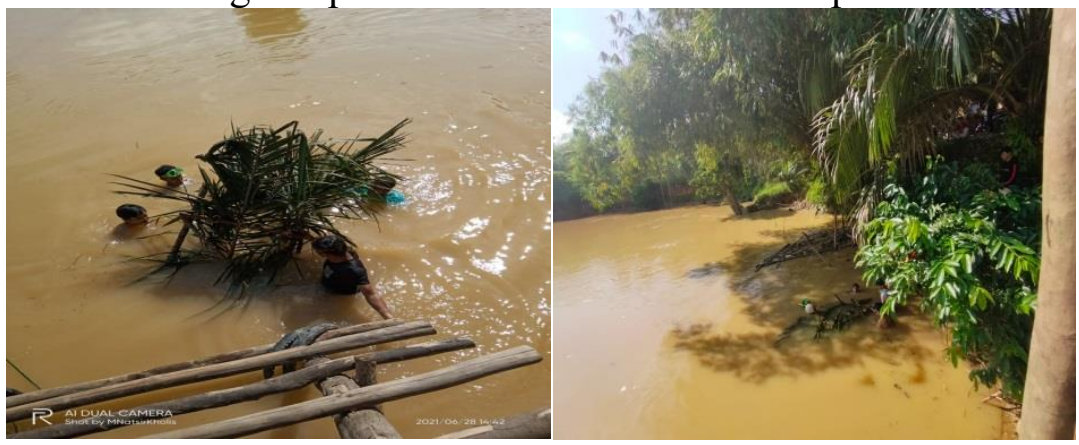

Gambar 5. Pemasangan Rumah Ikan (Rumpon)

\section{Pendampingan dan Evaluasi}

Tahapan terakhir dari pengabdian masyarakat ini yaitu pendampingan dan evaluasi. Tahapan ini dilakukan setelah pemasangan rumpon di lubuk larangan, dalam jangka waktu satu bulan untuk mengamati ketertarikan ikan terhadap rumpon yang dibuat. Selain itu dalam tahapan ini masyarakat juga dibantu dalam menghitung biaya pembuatan, perawatan hingga panen lubuk larangan. Dari hasil evaluasi biaya pembuatan dan perawatan menghabiskan dana sekitar Rp.3.500.000,- / per tahun. Menurut Kholis et al., (2020) pembuatan rumpon lubuk 
larangan dibuat sedemikian rupa dengan memerhatikan jangka waktu pengoperasian, untuk itu digunakan bahan-bahan dengan kualitas terbaik. Hal itu menyebabkan biaya awal untuk pembuatan rumpon lubuk larangan terbilang tinggi bagi masyarakat desa, tetapi tidak menutup kemungkinan bahan material dapat diganti sesuai kebutuhan masyarakat desa. Biaya bahan habis pakai pembuatan rumpon lubuk larangan yaitu sebesar Rp.770.000,- dan biaya pengadaan alat sebesar Rp.465.000,- sehingga total biaya pembuatan sebesar Rp.1.235.000,--

Hasil pendampingan dilihat dari kondisi lapangan, ikan-ikan sangat tertarik mendekati rumpon yang telah dipasang. Terlihat jelas ikan-ikan berkumpul dan berasosiasi disekitaran rumpon. Percikan air lompatan ikan saat diberi makan menandakan keberadaan ikan disekitar rumpon. Hasil wawancara dengan masyarakat juga menunjukan bahwa rumpon yang dipasang di lubuk larangan tebat dapat dikatakan berhasil memikat ikan untuk dapat berkumpul di area rumpon yang dipasang.
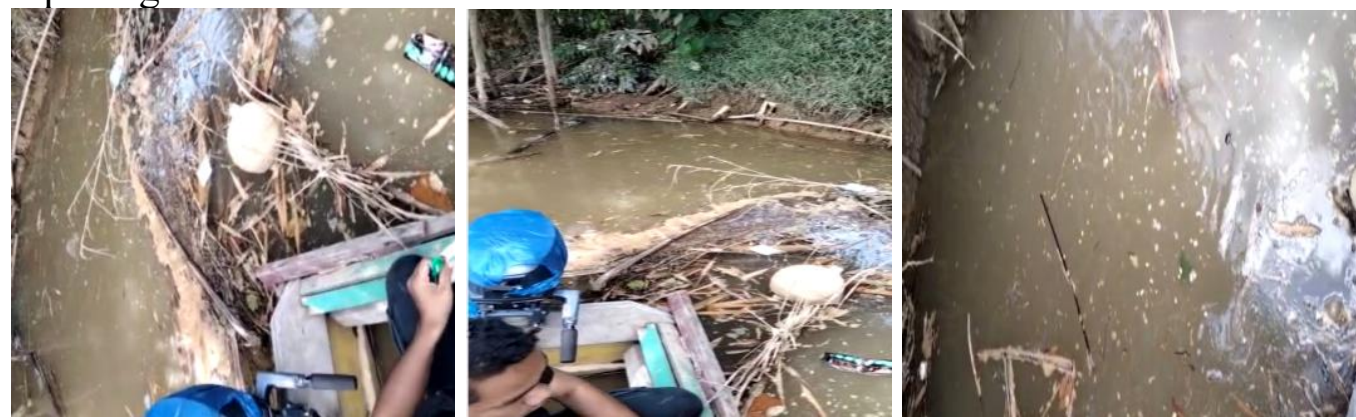

Gambar 6. Pemantauan Rumah Ikan (Rumpon)

Tahapan evaluasi dilakukan dengan cara melihat partispasi masyarakat dalam menjaga rumpon, lubuk larangan dan keberlanjutan sumberdaya perikanan yang ada di desa tebat. Hasil pengamatan dan wawancara menunjukan masyarakat sangat partispatif dan memiliki harapan yang tinggi terhadap rumpon yang dipasang, agar mampu memikat ikan sehingga berkumpul di lubuk larangan sampai waktu panen tiba.

Menurut Jeujanan et al., (2016) rumpon merupakan alat pengelolaan perikanan berkelanjutan. Dengan memberikan perhatian utama pada aspek keberlanjutan masyarakat perikanan sebagai sebuah sistem komunitas. Konsep perikanan tradisional yang terbuka mampu melakukan pengawasan sendiri (selfcontrol) terhadap hasil tangkapan, penggunaan teknologi penangkapan yang sesuai, adanya kebersamaan yang tinggi antara anggota masyarakat serta adanya pengetahuan tradisional yang mencerminkan upaya ketahanan dalam jangka panjang, merupakan faktor penting dalam pendekatan ini. Dengan demikian, perikanan yang berkelanjutan tidak semata-mata ditunjukan untuk kelestarian sumberdaya ikan itu sendiri atau keuntungan ekonomi saja, akan tetapi lebih dari itu keberlanjutan komunitas perikanan yang ditunjang oleh keberlanjutan kelembangaan suatu kebijakan dari status keberlanjutan pembangunan perikanan berbasis rumpon yang terintegrasi dari seluruh komponen (secara holistik), baik aspek ekologi, teknologi, ekonomi dan sosial. 


\section{KESIMPULAN}

Hasil pengabdian masyarakat ini dapat disimpulkan bahwa masyarakat masih belum banyak mengenal rumpon, pembuatan rumpon dilakukan bersama masyarakat dan dioperasikan di lubuk larangan tebat. Konstruksi rumpon yang dibuat memliki pelampung berdiameter $80 \mathrm{~cm}$ dan tinggi $30 \mathrm{~cm}$, tali berbahan PE dengan panjang $1.5 \mathrm{~m}$ berdiameter $1 \mathrm{~cm}$, badan rumpon terbuat dari rangka bambu dan kayu berukuran panjang $80 \mathrm{~cm}$, lebar $50 \mathrm{~cm}$ dan tinggi $1.54 \mathrm{~m}$. Atraktor rumpon yaitu daun sawit panjang $1.9 \mathrm{~m}$ berjumlah 5 helai serta pemberat berbahan semen.

\section{DAFTAR PUSTAKA}

[CIFOR] Center for Internasional Forestry. 2008. Belajar dari Bungo 'Mengelola Sumberdaya Alam di Era Desentralisasi. Bogor. 498 hal

[Disnakkan] Dinas Peternakan dan Perikanan. (2018). Laporan Tahunan Statistik Perikanan Tangkap Dinas Peternakan dan Perikanan Kabupaten Bungo, Muara Bungo Provinsi Jambi. Jambi: Disnakkan.

Handayani, M., Djunaidi, \& Hertati, R. (2018). Sistem Pengelolaan Lubuk Larangan Sebagai Bentuk Kearifan Lokal di Sungai Batang Tebo Kabupaten Bungo Provinsi Jambi. SEMAH: Jurnal Pengelolaan Sumberdaya Perairan, 2(3).

Harizon, H., Hertati, R., \& Kholis, M. N. (2020). Tingkat Partisipasi Masyarakat Terhadap Suaka Perikanan (Reservat) Lubuk Kasai Perairan Batang Pelepat Kabupaten Bungo Provinsi Jambi. SEMAH Jurnal Pengelolaan Sumberdaya Perairan, 4(1).

Hikmah, N., Kurnia, M., \& Amir, F. (2017). Pemanfaatan Teknologi Alat Bantu Rumpon untuk Penangkapan Ikan di Perairan Kabupaten Jeneponto. Jurnal IPTEKS Pemanfaatan Sumberdaya Perikanan, 3(6), 455-468.

Jeujanan, B. (2016). Rumpon Sebagai Alat Pengelolaan Perikanan Pelagis di Perairan Kepulauan Kei (Doctoral dissertation, IPB (Bogor Agricultural University)).

Kholis, M. N., Amrullah, M. Y., Martasuganda, S., \& Saputra, F. (2020). Studi Rancang Bangun Konstruksi Rumpon Lubuk Larangan di Kabupaten Bungo Provinsi Jambi. PELAGICUS, 1(2), 71-81.

Suardi. (2017). Rancang Bangun Rumpon Hidup (BioFAD) dan Uji Efektivitas Serta Keramahan Lingkungan di Perairan Pesisir Uloulo Kabupaten Luwu. Disertasi. Program Pasca Sarjana Institut Pertanian Bogor. Bogor.

Yusfiandayani, R., Jaya, I., \& Baskoro, M. S. (2014). Konstruksi dan Produktivitas Rumpon Portabel di Perairan Palabuhanratu, Jawa Barat. Jurnal Teknologi Perikanan dan Kelautan, 5(2), 117-127. 